\title{
Adequate Force Characteristics of a Friction System
}

\author{
Zdzisław Pluta, Tadeusz Hryniewicz* \\ Koszalin University of Technology, Raclawicka 15-17, PL 75-620 Koszalin, Poland \\ *E-mail address: Tadeusz.Hryniewicz@tu.koszalin.pl
}

„Contrary to the deep truth

there may be another deep truth."

Albert Einstein

\begin{abstract}
In the paper, at first some remarks concerning friction are presented by the definition of the friction itself, as well as its essential force characteristics. An adequate definition of friction is introduced, and moreover a correct its characteristics. Next the statics, dynamics, and kinematics of the friction system is given, forming the force characteristics of this system for each of the mechanical behaviours, taking into account real inertia forces of the body under friction. Three types of coefficients of sliding friction have been separated, namely: coefficient of static friction, dynamic friction, and kinematic friction. Then the comparative analysis of existent and new knowledge on the force characteristics of friction process has been presented. The consideration on how to determine the coefficient of static friction has also been carried out. Reflections on the possibilities to form further force characteristics of the friction process are presented to develop this work with some final remarks directing the attention on the conditions of development of science on friction.
\end{abstract}

Keywords: Friction; Friction system; Force of surface resistance; Coefficient of friction; Static friction; Dynamic friction; Kinematic friction; Triangle of friction; Passive zone of forces; Active zone of forces; Characteristics of friction process

\section{SOME REMARKS ON FRICTION}

There are lots of publications devoted to the friction phenomena and it would be rather difficult to get through all of them. Hence the interest in friction problems is immense and still open. There are a series of various factors, with the complexity covering a variety of materials, environments, and conditions affecting the problems of friction.

It seems to be, however, there is one more factor with insufficient attention paid until now, and it is simply the lack of a strict definition of investigation subject which is the friction.

The definitions found in the scientific-technical literature are varied. The friction has been considered as a force, phenomenon, set of phenomena, and sometimes it is called a process. Here are some examples taken right from the literature. 
It is worth beginning from a polemic name defined as follows [1]: ,, The friction force is a sliding force”. Next definition of friction [2] is as follows: ,, The friction is the phenomenon of arising resistance hampering the motion of two solid bodies one, against other, being in contact along some surface".

Now there is the book definition of friction, treating it also as a singular phenomenon [3]: „, The friction is the phenomenon of formation of tangent forces to the contact surface of two bodies. These forces are called friction forces. They may be defined as resistance forces, preventing the motion that could arise without friction. Thus they are passive forces, i.e. the reaction components which occur to conserve the equilibrium of contacting bodies".

The following is the example being another definition of friction, excerpted from the literature [4]. That definition says: „, The friction may be understood as a set of phenomena occurring between contacting bodies caused by action of a normal force pressed against the bodies and tangent force displacing them one against other (motion friction), or attempting to displace them (static friction)". Finally, the definition of a contact friction, treated as a process, presented by Bowden and Tabor [5] is as follows: „the process of periodic arising and destruction of intermetallic adhesive joints, created in the areas of a real contact of surfaces of contacting elements". That is a mechanical hypothesis of friction, further developed by other researchers.

The molecular-mechanical theory of friction, elaborated by Kragielski [6], is a development of the mentioned Bowden and Tabor's concept. It assumes that the friction resistance is the result of mechanical reactions of roughness of two rubbing surfaces, as well as molecular reactions resulting from approaching/contacting two bodies.

This and other theories, presented e.g. by Drescher [7], Dieriagin [8], Rabinowicz [9], are concentrated on the attempt to describe the so called friction force. They attempt to explain and describe the friction process by connecting this mentioned force with many different component factors. A thermodynamic approach [10-14] has been used in attempt to describe the process. All those actions are still focused on the contact zone of rubbing material bodies.

It appears the whole friction system, being the basis of the friction laws, is still considered as a known Coulomb and Moren model. One of the friction law says that the "friction force" is independent on the magnitude of surfaces of contacting bodies and depends on their type only. The value of the "friction force" for a body being at rest may change from zero to a limiting value, and that is the second law of friction. The third one explains that once the body slides on a surface, the "friction force" is always directed against the motion direction and is less than the limiting value.

The present work is linked to such a system of material bodies as well as the rules describing the behaviour in view of presenting the adequate force characteristics of a friction system. This is why the need to assume a proper definition of the friction itself, as well as the magnitudes connected with it, occurs.

There is no doubt the friction is a process. This may be found in [15-19]. An additional confirmation of justness of naming the friction as a process is a remark that the friction may be as intended and controlled. That surely qualifies it to a treatment process. A significant example of friction, as a process, may be the so called mutual lapping of ceramic elements [20]. Therefore in the chain of reason-effect the phenomena are treated as the second element, naming them as the friction phenomena, i.e. the phenomena caused by the friction.

Therefore the definition on friction may be written as follows: ,, The friction is a process with a determined contact or in-depth phenomena occurring in it". Its other definition version could be as follows: ,, The friction is a process of creation of different structure in subsurface layers in the rubbing bodies". 
Now we arrive to a proper name of this most characteristic process of friction, and it is about the so called a friction force. Unfortunately the „friction force” as inadequate term is still in common use even if its language structure is not in agreement with its proper meaning. The name of force should result from its essence, i.e. the reason of arising determined effects of material bodies interactions. In the process of external friction the reason is the surface resistance. Thus based on the reason-effect relation the definition of the force should be substituted by a correct name as the „force of surface resistance”.

Therefore, having the correct definition of friction with a proper determination of its most important characteristics, one may come to the adequate description of force characteristics of the whole friction system. This is the basis of the work.

\section{STATICS, DYNAMICS AND KINEMATICS OF THE FRICTION SYSTEM}

A fundamental condition of adequate description of force characteristics of the friction system takes into account the statics, dynamics, and kinematics. The statics and kinematics are the basis of energetic states of the system. Between these states there is dynamics, i.e. the variable relative motion of rubbing solid bodies. Such a system approach to the problem will allow to achieve the cognitive aim.

One may notice the criterion of the mentioned solid bodies behaviour is their reference to the motion. The statics means zero motion, or standstill; the dynamics determines variable motion of the system; kinematics appears in case once the bodies, both rubbing and rubbed, move one against another with a uniform motion. Thus the forces do not decide of dynamics. They are and must be the measure of each of these three synergistic actions of the elements of the friction system.

It is worth mentioning that just the new adequate approach to the issue of friction has been introduced to the scientific literature. It was about a specific machining system, concerning the abrasive grain-machined material system, with the grain having its flexible restrain/fixing. This problem, with its energetic-dynamic aspect, has been considered in [2, 20-25].

Let us consider first the friction system being in standstill. The body rests on a determined material base. That means the relative velocity of the two of these bodies is zero. From the energetic point of view these bodies are in the state of a stable static energetic equilibrium. Thus the values of all forces in the horizontal direction are equal, and their senses are reversal. The same concerns the vertical direction.

The whole force space is passive, with the surface resistance forces $T_{1}, T_{2}$ (tangent components of reaction), horizontal inertia forces $B_{1}, B_{2}$, component normal force $N$, reaction forces $R_{1}, R_{2}$, and inertia force $Q$, being in this space (Fig. 1); in this space the inertia force is co-existing with the vertical gravitation inertia force $B_{Q}$, noted by the apparent relation as $Q \otimes B_{Q}$. 


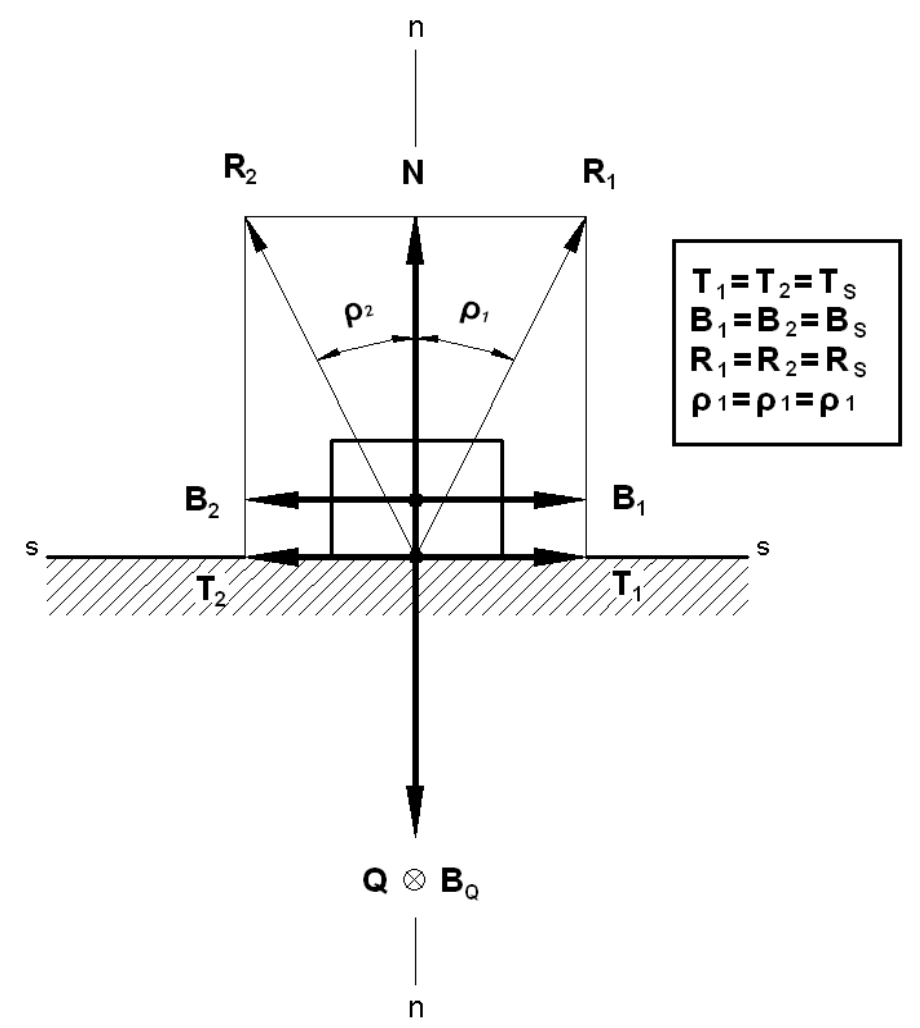

Fig. 1. Force space of friction system being in a stable energetic equilibrium

The reaction forces $R_{1}, R_{2}$ are the arms of the so called triangle of static friction. That is an isosceles triangle of friction. Its arms have angle positions/orientations against the height corresponding with the normal component of reaction $N$. These positions are determined by the angles $\rho_{1}, \rho_{2}$, named by the friction angles. It is worth admitting that the qualification of "friction triangle" is more justifiable than functioning until now the "friction cone". The last one, existent term may reflect eventually the static conditions only. It does not correspond with dynamic and kinematic conditions and it will be discussed furthermore.

Under the considered conditions, static conditions of friction, there is a symmetry of all forces. Therefore the following force relations: $B_{1}=B_{2}=B_{s}, T_{1}=T_{2}=T_{s}, R_{1}=R_{2}=R_{s}$, as well as angular relation: $\rho_{1}=\rho_{2}=\rho_{s}$ may be referred to these conditions. Symbol $B_{s}$ denotes the static inertia force (standstill, initial), $T_{s}$ is the force of static surface resistance, $R_{S}$ is the force of static reaction, and $\rho_{s}$ is the angle of static friction.

The stable static energetic equilibrium of this friction system may be generally written by the following relationships:

$$
\begin{aligned}
& \sum_{i=1}^{s} F_{i}=0 \\
& \sum_{j=1}^{n} F_{j}=0
\end{aligned}
$$

with

$$
F_{1}=F_{2}=F_{3}=\ldots=F_{i}
$$




$$
F_{1}=F_{2}=F_{3}=\ldots F_{j}
$$

That means, the algebraic sum of all forces of the system on all its directions (horizontal $s$, and vertical $n$ ) is zero, and the values of particular forces on these directions are equal. Thus on the horizontal direction $B_{s}=T_{s}$, and on the vertical direction $N=Q \otimes B_{Q}$.

Here is another characteristics of the system. This is the coefficient of static friction $\mu_{s}$. It has been defined by the ratio of force $T_{s}$ to the normal component $N$ of reaction, that is

$$
\mu_{s}=\frac{T_{s}}{N}
$$

This coefficient is equal to the tangent of angle of static friction, then $\mu_{s}=\operatorname{tg} \rho_{s}$.

The described a stable static energetic state of the considered system reflects also the closed polygon of all forces (Fig. 2). In this Figure, there are also additional resultant forces $T_{1}, N$ and $T_{2}, N$, or $R_{1}$ and $R_{2}$.

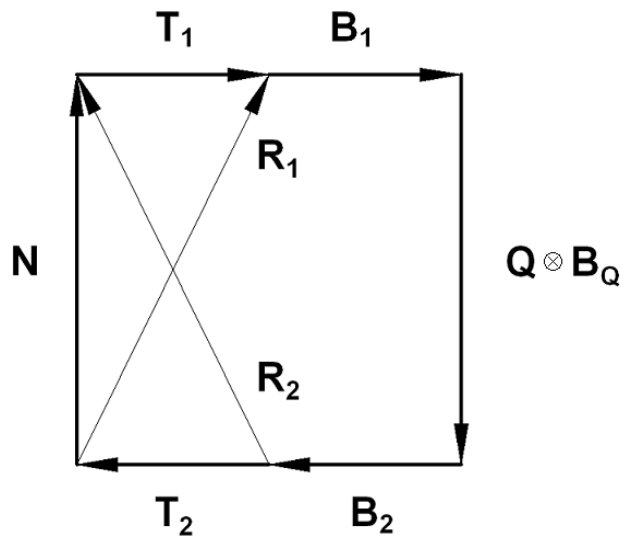

Fig. 2. Closed polygon of component forces referred to a stable static energetic state of friction system

Now the dynamics system is to be described. The rubbing body is provided with the variable motion, and it is the accelerated variable motion. It is possible by using a determined external stimulus which is another body and acts on the rubbing body with a determined force $F$. In this case the force will substitute an inertia force, for instance $B_{1}$ (when the motion will proceed in the right side), or this action may be gradual. In the first case it is a rigid driving system, whereas the gradual substituting of inertia force $B_{1}$ by the driving force $F$ occurs if the driving system has an elastic character. That means further the force growth $F$ is accompanied by a decrease (down to zero) of inertia force $B_{1}$, of course at a standstill body being initiated with a variable motion.

An active force zone has appeared (right dotted part of the whole force zone in Fig. 3), whereas the left part is still passive (Fig. 3). Now the right reaction force $R_{l}$ will decline into the direction of the normal component reaction $N$, resulting in the decrease of resistance force $T_{1}$. The active force $F$ must increase in a proper way.

The inertia force $B_{2}$ still increases, whereas the surface resistance force $T_{2}$ is getting lower and lower. That means the reaction force $R_{2}$ is also directed to the direction of a normal force $N$. 


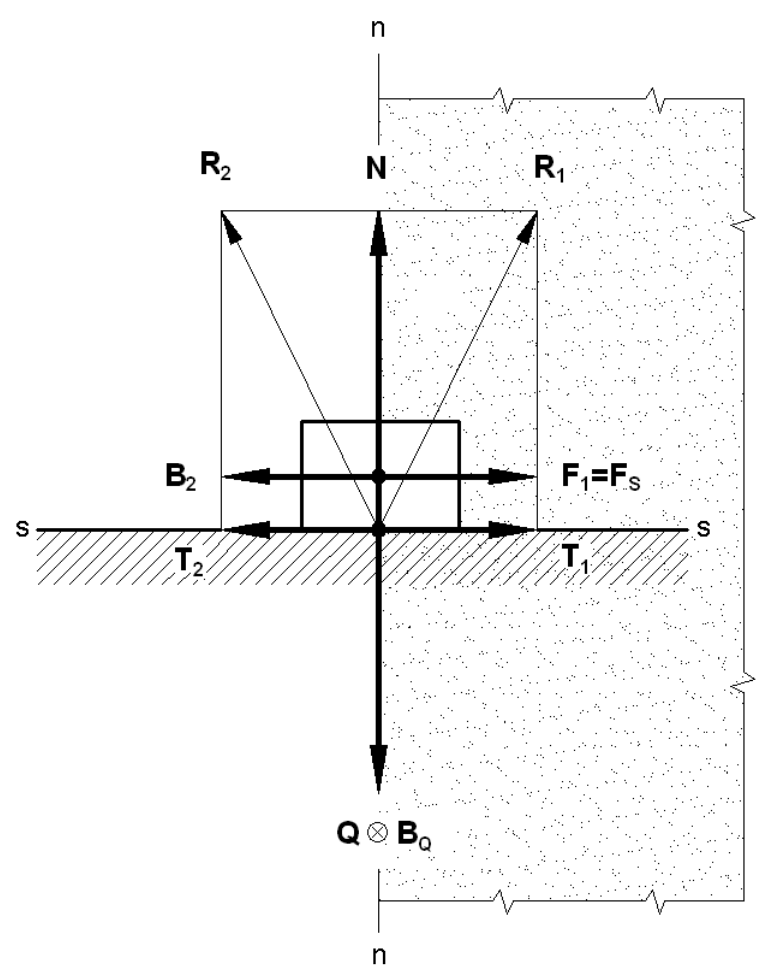

Fig. 3. System of component forces in the moment of beginning of rubbing body motion.

Therefore all the forces (Fig. 4) change their values respectively. Ones of them grow, others decrease. At the moment it is impossible to illustrate this situation by means of a closed polygon of forces as they are not in equilibrium.

This is just a significant feature of dynamics of all material bodies and their complex systems. It does not make any sense then to introduce there any fictional inertia forces (according to the so called d'Alembert's rule) [26] only to form an apparent equilibrium. Any real force here should be considered separately. In fact, the real inertia forces also exist. However, a proper approach and understanding is necessary and for this a separate work has been devoted [27]. The dynamics of a rubbing body may be described by two types of coefficients of the dynamic force. One of them is the coefficient of active dynamic friction $\mu_{1}$, being the ratio of surface resistance force $T_{l}$ and a normal reaction component $N$, that is

$$
\mu_{1}=\frac{T_{1}}{N}
$$

The second characteristics of this type is the coefficient of passive dynamic friction $\mu_{2}$. This coefficient, in turn, is the ratio of surface resistance force $T_{2}$ to the nominal reaction component $N$, then

$$
\mu_{2}=\frac{T_{2}}{N}
$$

And now is the time for the analysis of kinematic energetic equilibrium of a rubbing body. That type of equilibrium takes place after the transition of this body through the spacetime, which is the site where its dynamics took place, so it is under the variable motion (here, accelerated variable motion). 


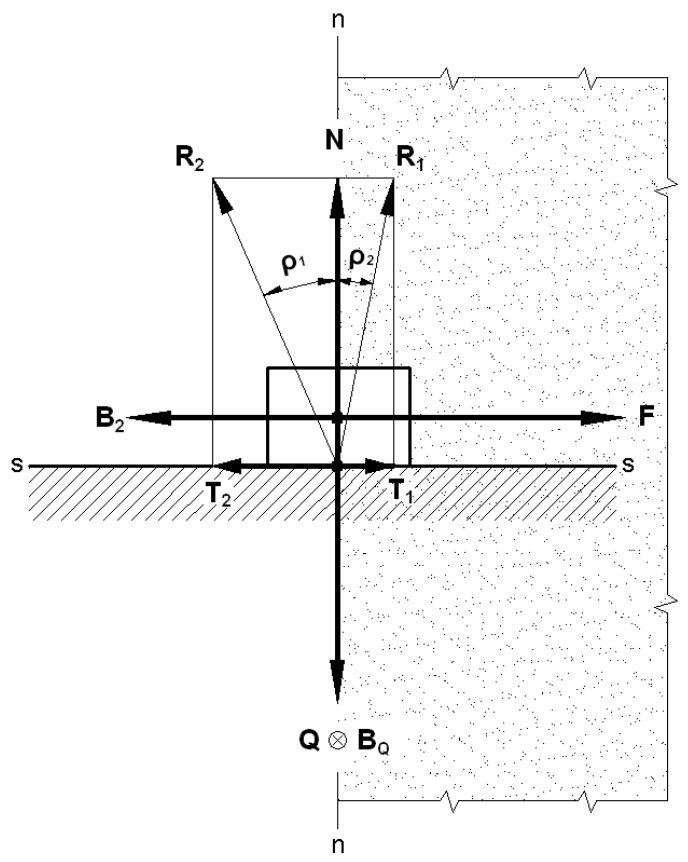

Fig. 4. Force system referred to a rubbing body moving with accelerated variable motion.

The surface resistance force $T_{1}$ has disappeared, and there is only a driving force $F$ (Fig. 5) on the active side and the body moves with a uniform motion. Hence all the remaining horizontal forces may be described as follows: $T_{2}=T_{k}, B_{2}=B_{k}, R_{2}=R_{k}, F=F_{k}$, and the angular magnitude $\rho_{2}=\rho_{k}$. In the vertical direction the force relations have not undergone any change.

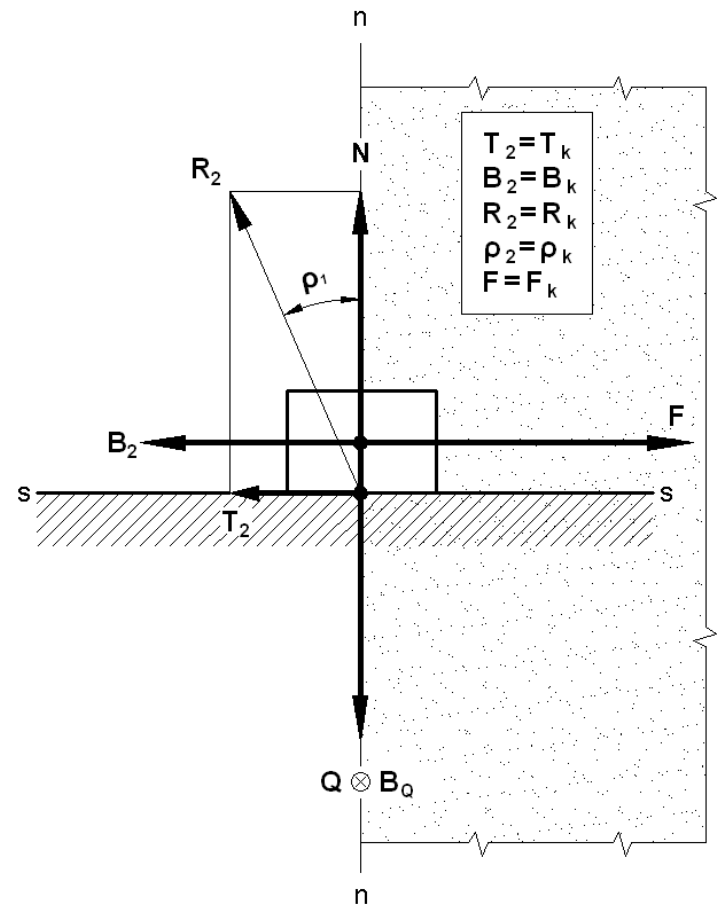

Fig. 5. Vector configuration of forces for kinematic energetic state of rubbing body 
This equilibrium is illustrated by the closed polygon of forces (Fig. 6). In Figure 6 the resultant of forces $T_{2}$ and $N$ has been introduced.

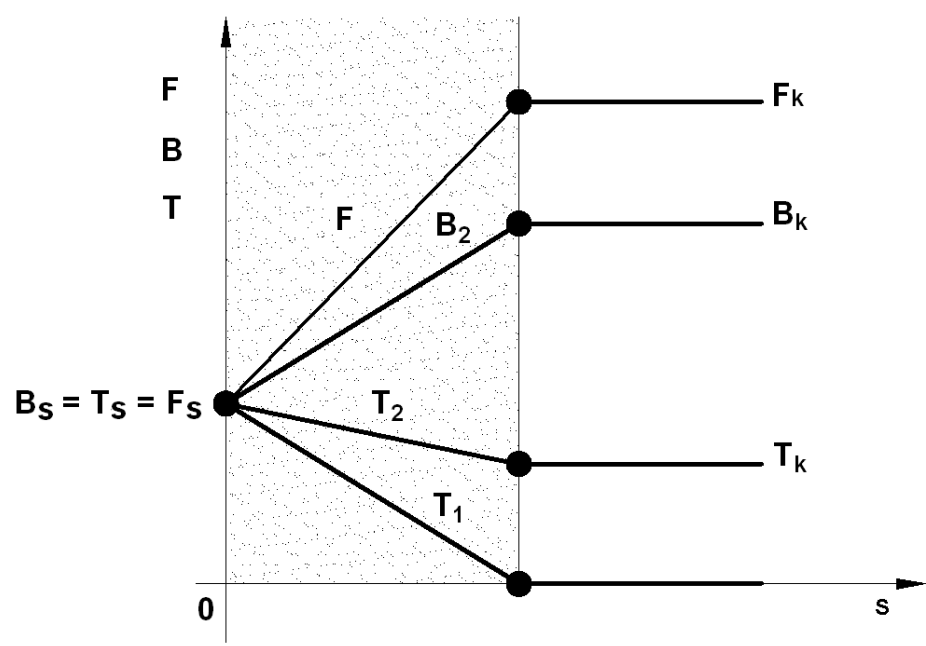

Fig. 6. Polygon of forces illustrating kinematic energetic equilibrium of a moving material body.

The condition of kinematic energetic equilibrium may be written in general. It is only partly similar to the conditions of static equilibrium. Both types of equilibria include the records (1), (2), and (4), whereas the record (3) is different in its form, i.e.

$$
F_{1} \neq F_{2} \neq F_{3} \neq \ldots \neq F_{i}
$$

That means the values of particular forces in the horizontal direction are different.

For the considered specific system that equilibrium of forces in the horizontal direction is as follows:

$$
F_{k}=B_{k}+T_{k}
$$

Now here is the synthesis of force characteristics of a rubbing system (Fig. 7), presenting the courses of component forces as the function of path length $s$ of a rubbing body. It contains all three particle characteristics concerning statics, dynamics, and kinematics of the considered system. Clearly visible are variabilities of particular forces in the interstate space (see Fig. 7). These courses of forces in the space-time are naturally respectively non-linear. That is the time factor which introduces the non-linearity.

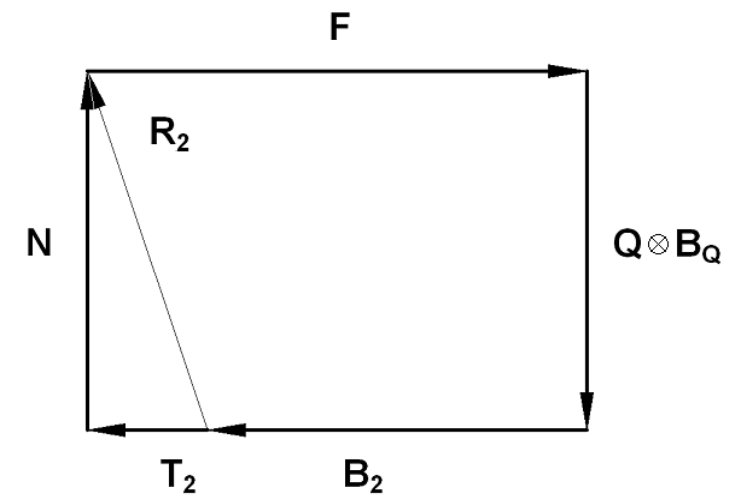

Fig. 7. Force characteristics illustrating the statics, dynamics, and kinematics of rubbing body. 
At the beginning of the body start-up the component forces are equal as to their values. At the end of the start-up, at the moment of change of the body motion into uniform one, the values of forces are different and a kinematic equilibrium between them occurs. Following the uniform motion that equilibrium is retained. One may add that at the stage of braking/ retardation where the retarded variable motion takes place, the courses of all these forces will be a mirror reflection of their courses in the accelerated motion.

At the end it is worth adding the characteristics of friction process (Fig. 8), being the dependence of surface resistance force $T$ on the driving force $F$. This Figure 8 explains the variability of forces for elastic driving system when the driving force varies within the limits from zero to the value of static friction force $F_{s}$, and active inertia force $B_{1}$ decreases to zero. Marked there are also the variabilities of surface resistance dynamic forces, i.e. $T_{2}$ and $T_{1}$, taking place in the interval of force changes $F$ from $F_{s}$ to $F_{k}$ which are kinematic friction forces.

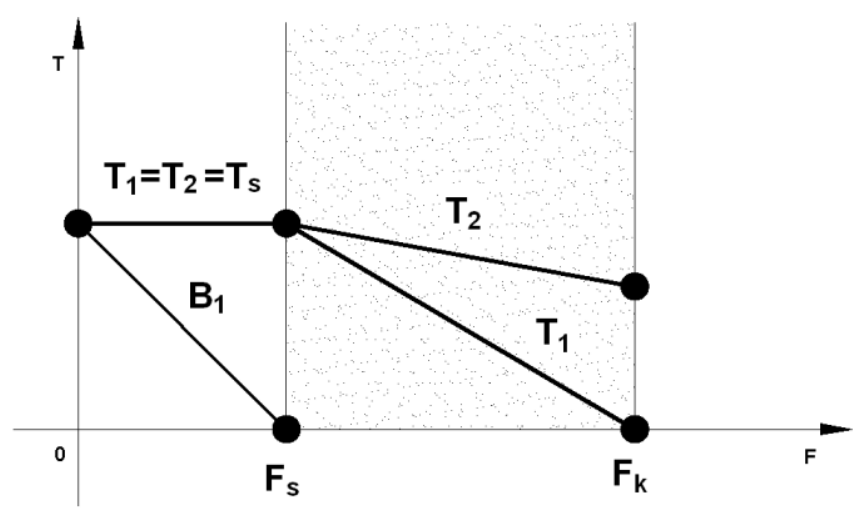

Fig. 8. Dependence of force surface resistance on the driving force for elastic driving system.

\section{COMPARATIVE ANALYSIS OF EXISTENT AND NEW KNOWLEDGE ON THE FORCE CHARACTERISTICS OF FRICTION PROCESS}

The existent knowledge on the force characteristics of friction process has a non-ordered non-uniform character. It possesses several cognitive defects. It has no clear transparent organization. That all is surely an essential barrier for a rational development of this knowledge on tribology.

There are some examples of removal obstacles on the way to cognition of the reality, as presented in [28], however, with no effect as yet leaving it in the area of potential possibilities. Here is a statement of the author of this work [28]: „, From time to time there are some discoveries appearing in science which clearly collide with the existent interpretations. The scientific problems may arise that cannot be solved using the cognition system of recognized paradigm. The controversial results and non-solved problems are put aside for some time because the scientific society is reluctant to part with the earlier recognized paradigm".

One may say it is a kind of a frank/pure statement, and as it appears, it does not correspond with the title of the work [28]: „Development of tribology in the light of correctness of the science progress", as one cannot assume this reluctance to accept new descriptions of reality to be recognized as correct on a cognitive basis.

It is worth noticing that the up-to-date friction models do not take into account all component forces. The inertia forces, real inertia forces which de facto exist, are completely 
omitted. They, together with the surface resistance forces, cause the body to be set in a variable motion, and then the uniform motion, with the result the action of some determined external stimulus is needed.

The existent force structures of the friction process are assumed erroneously that, in a body standstill state, there are no forces in the direction of potential motion. And they are for sure but exist under a stable static energetic equilibrium.

One should admit that the up-to-date knowledge on friction unfortunately leaves out the dynamics of the friction system. There is no mention about the non-linearly variable motion of the system bodies, nor of its indispensable transition through the space-time in view of getting to a kinematic energetic state.

Characteristics of the friction process, built on the basis of such inadequate models, are quite simplified, not clear, not transparent, and thus incoherent with the studied reality. Therefore it may be troubling, e.g. for a computer simulation of such processes, that has been marked in the work [29].

After presented the analysis of statics, dynamics, and kinematics of the friction system one may refer to the model of Coulomb and Moren and formed on its basis the rules of friction (see Chapter one). As far as the first law, saying of the independence of ,friction force" (and it is rather on the surface resistance force) on the surface magnitude may be accepted, so the following two laws cannot be recognized as adequate ones.

The value of surface resistance force for a body being standstill, according to the second law of friction, cannot change from zero to a limited value. That way may change the driving force, resulting from the action of a determined external stimulus, as illustrated in Fig. 8. The surface resistance force under the body standstill is determined and invariable.

The third known law of friction also has its unclear contents. It says that once the body slides on some surface then the "friction force" is always directed against the direction of motion and is less than a limiting value. And that is true but only in case if the body is in the kinematic energetic state that refers to its uniform motion. If the rubbing body moves with an accelerated variable motion or retarded variable motion then, as indicated, the active and passive surface resistance forces occur. The first one is directed into the body motion direction and decreases assuming the values from the limiting value to zero. The second surface resistance, the passive one, has its reverse sense to the sense of the body motion and decreases from a limiting value to such one which corresponds with a uniform motion of this body.

\section{ON THE DETERMINATION OF COEFFICIENT OF THE STATIC FRICTION}

It is known that the simplest and common way of determination of the coefficient of static friction (standstill) relies on placement of the rubbing body on the inclined plane having the carrying surface of characteristics of rubbed body. Then such a loaded carrying surface is positioned under the angle corresponding with the beginning of rubbing body motion. Tangent of this angle is, according to the existent theory, equal to the coefficient of static friction between mutually working elements of the friction system.

That was about determination of the coefficient of static friction. From the scientific viewpoint the study method itself is more important as in its essence it should cover the adequate theory that is a true description of the studied reality. The existent theory, however, does not correspond with the reality. Its use leads to obtaining analogous values of the friction coefficient. However, the definition components of this coefficient, i.e. $T_{s}$ and $N$, presented in 
the formula (5) differ as to the values, assuming according to the existent theory some lower values.

A new adequate theory, presenting the essence of the method of determination of static friction coefficient is to be provided. It will allow to determine the real values of definition components of this coefficient. The way and/or measurement technique of this limiting friction angle will not undergo any change.

Herewith, in Fig. 9 is the system of all forces, referred to the unstable static energetic equilibrium, being on the inclined plane. It is worth noting that on a horizontal surface the body would be in a stable equilibrium. In Fig. 9 there are three essential directions marked: tangent $s-s$, normal $n-n$, and vertical $v-v$. The tangent direction is equal with the direction of the inclined plane, normal is situated perpendicularly against it, and vertical corresponds with the direction of gravitation force.

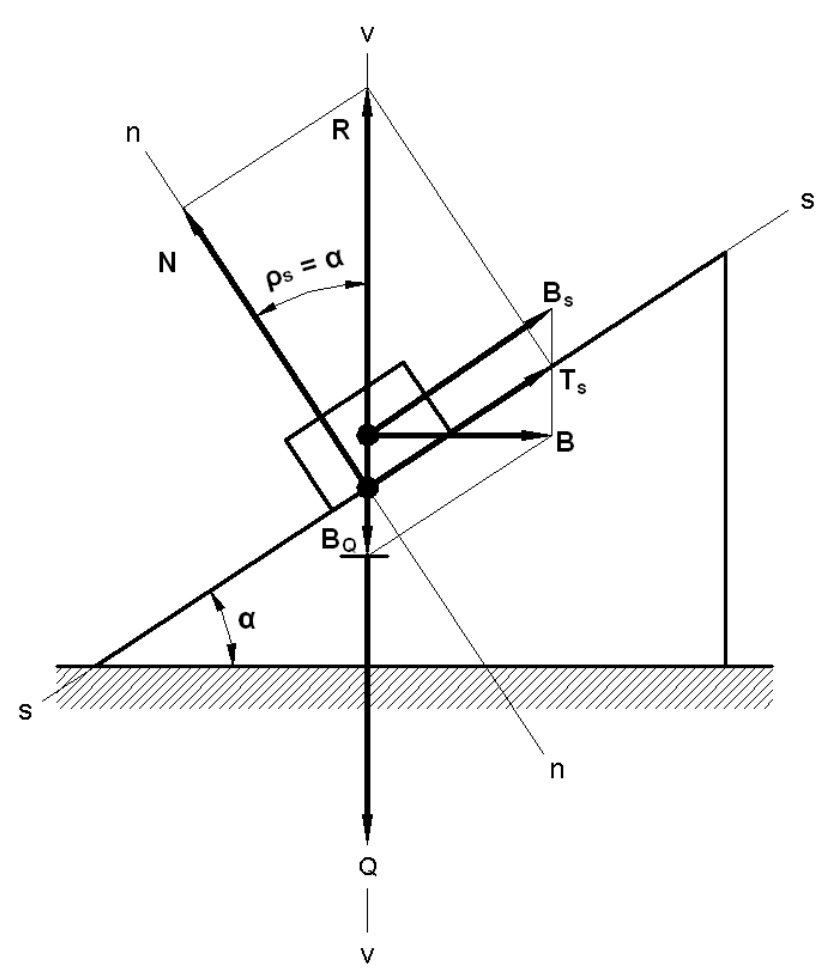

Fig. 9. All-force system referred to the unstable static energetic equilibrium of a rubbing body being on an inclined plane.

As far as in the stable state on the direction of the gravity force $Q$ the gravity inertia force $B_{Q}$ was with the first one in co-existence state $\left(Q \otimes B_{Q}\right)$, so the former one reveals and marks its existence clearly. In an unstable state it is equal as to the value to the half of gravity force $\left(B_{Q}=0.5 Q\right)$. Due to a limited space of this work the proof of this relation has been omitted, but given in [24]. The sum of the mentioned forces corresponds with the balancing reaction force $R$, and the following relationship occurs between them:

$$
B_{Q}+Q=\frac{Q}{2}+Q=\frac{3}{2} Q=R
$$


The gravity force, especially worth stressing, is characterized by an invariability of its direction. Therefore it absolutely cannot be divided into components as it is done with the inertia force, the real inertia force.

The directions of inertia force $B_{s}$ and the static surface resistance $T_{s}$ correspond with the tangent direction. They have equal values. There is no force equilibrium on this direction. One may add the forces $B_{S}$ and $B_{Q}$ are components of the resultant inertia force $B$, which does not overlap the normal direction.

On the normal direction there is a normal reaction force $N$, declined from the force $R$ of the static friction angle $\rho_{s}$, equal to the angle $\alpha$ of the inclined plane on which that rubbing body rests.

The whole system is in a static equilibrium reflected by the closed polygon of all forces (Fig. 10). That polygon is here the rectangular triangle.

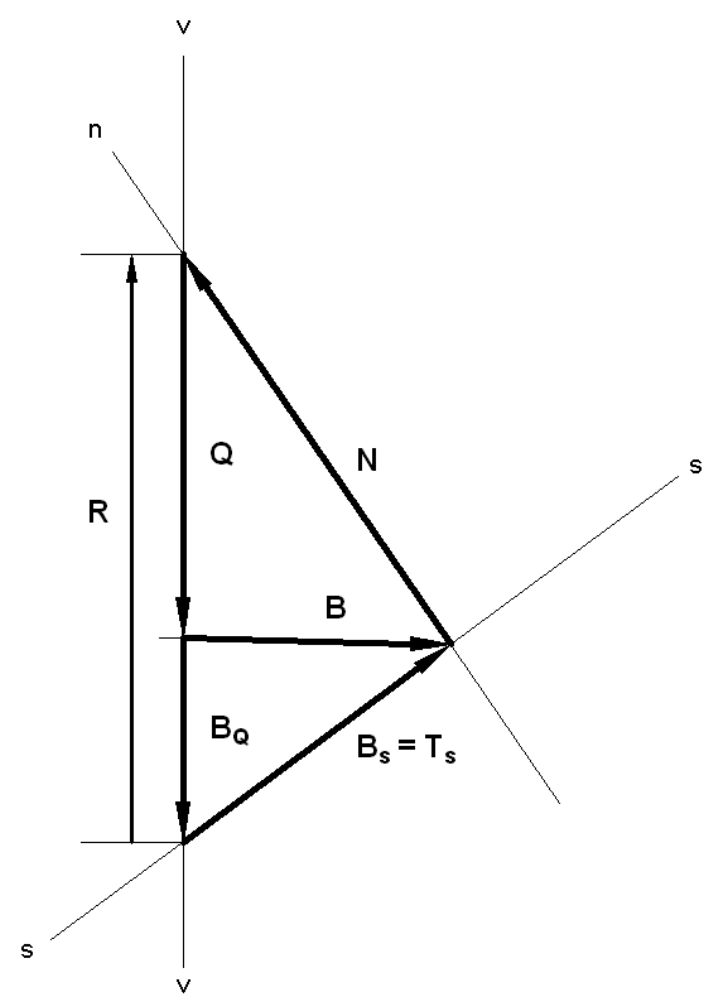

Fig. 10. Triangle of the component forces illustrating the static limiting equilibrium of a body being on inclined plane

The coefficient of static friction, described by formula (5), needs to determine the force of static surface resistance $T_{s}$ and the component of normal reaction $N$. From the system of forces (see Fig. 9) it results that

and

$$
T_{s}=R \sin \rho_{s}
$$

$$
N=R \cos \rho_{s}
$$

then

$$
\mu_{s}=\frac{T_{s}}{N}=\operatorname{tg} \rho_{s}=\mu_{s}
$$


It appears the new theory leads to an analogous result concerning the coefficient of static friction, however, relating the values, the force of static surface resistance $T_{s}$, as well as the normal component of reaction $N$, are quite different. The up-to-date knowledge provides the following connections:

$$
\begin{aligned}
& T_{s}=Q \sin \rho_{s} \\
& N=Q \cos \rho_{s}
\end{aligned}
$$

whereas, after taking into account the record (10) in the formulae (11) and (12), one obtains

$$
\begin{aligned}
& T_{s}=\frac{3}{2} Q \sin \rho_{s} \\
& N=\frac{3}{2} Q \cos \rho_{s}
\end{aligned}
$$

It results from the considerations that the interpretation differences in the descriptions of this part of reality are considerable and quite essential. The new adequate theory includes the inertia force, and moreover it correctly treats the gravity force, not decomposing it into components. From this the mentioned differences between existent and new friction theory result by presenting that friction process concerned with force characteristics.

\section{ON THE POSSIBILITIES OF CREATION FURTHER FORCE CHARACTERISTICS OF THE FRICTION PROCESS}

Further force characteristics of the friction process, coefficients of static, dynamic, and kinematic friction - everything may be formed and determined by a broad consideration of statics, dynamics, and kinematics of the friction system. For this purpose the particular behaviours should be described coming out of the source, initial characteristics which is the dependence of the body path length $s$ on time $t$ of its motion.

The mentioned characteristics, presented in [24, 30-36], has the following form:

$$
d s= \pm \frac{\partial s}{\partial t} d t
$$

where symbol $d s$ means the total differential of the path length, $d t$ - total differential of time, $\partial \mathrm{s} / \partial t$ - partial derivative of the path length on time. Symbols $( \pm)$ are the algebraic operators, with the operator $(+)$ confirming just the physical sense/meaning of determined record, and the sign (-) assures such a sense of the considered record [31-36].

The solution of that equation is also given in $[24,36]$. For the accelerated motion it takes the configuration:

$$
s=s_{0}\left(e^{\frac{t}{T}}-1\right)
$$


where $s_{o}$ denotes the body path length between its static and kinematic energetic states, i.e. on the space-time length where the variable motion takes place, in this case the accelerated variable motion; symbol $T$ denotes the so called time constant, which is the time of body transition onto the neighbouring energetic level (potential field), with a uniform initial velocity.

Now the consecutive kinetic magnitudes may be determined, for instance: velocity $v$, acceleration $a$, and impulse $i$. They are the first, second, and third derivatives of the path length against time, respectively. Then taking into account the body mass $m$, one may naturally determine the inertia force: initial $B_{o}$, relating to the static inertia force $B_{s}$, final or kinematic inertia $B_{k}$, as well as dynamic, passive inertia force $B_{2}$ (see Fig. 4).

Having these magnitudes, and taking advantage of the equation (9), one may further determine the force of kinematic surface resistance $T_{k}$. Afterwards it is possible to determine the coefficient of kinematic friction $\mu_{k}$-according to its known definition, that is

$$
\mu_{k}=\frac{T_{k}}{N}
$$

or

$$
\mu_{k}=\frac{T_{k}}{Q}
$$

as $N=Q$, if the motion occurs in horizontal direction, as such a motion variant is possible.

It is also possible to determine the coefficients of dynamic friction $\mu_{1}$ and $\mu_{2}$, respectively, following the formulae (6) and (7). The values of these coefficients are within the limits $\mu_{s}>\mu_{1}>\mu_{k}$, and $\mu_{s}>\mu_{2}>0$.

At present one may create lots of different force characteristics of the friction process by expressing all forces in the function of time $t$, path length $s$, acceleration $a$, and the impulse $i$. It is possible also to build the dependences between particular forces. That is a number of potential images of behaviours of rubbing body or the system of two bodies (rubbing and rubbed), if their relative motion is taken into consideration.

The limited frames of the work do not enable to develop the subject. This is why just the possibilities of further actions to develop the knowledge on friction is presented, not providing their detailed solutions. That may be the subject of the following papers.

\section{CONCLUSION}

In the summary it is worth mentioning that the presented force characteristics of a sliding friction process is different from the existent one, still in use the description of the force space of this process. This new adequate approach complies with the energetic states of rubbing body as well as the dynamics of the body.

At creating the theory of friction it has been respected that the real mass system possesses a determined inertia with the inertia force as its measure. That force, and it should be stressed, has no fictional character. Thus it does not undergo a paradigm, with the content covered by the so called d'Alembert's rule [26], saying about a fictional inertia force introduced to the system only to create a balance, the apparent force equilibrium.

The new presented herewith the theory of friction respects one more significant thing. It is consistent with the natural law referred to the gravity force. That force has a determined direction and cannot be decomposed into components forming the gravity force. That way 
only the inertia force may be decomposed. Thus the solution of basic problem of friction is possible.

The knowledge on friction cannot undergo a domination of Newton's mechanics because there are no adequate tools of description of the considered reality. That problem was stressed also by Osiński [37] who advised the scientists to pay more attention on the way to the truth. In his work he notices that the cognitive activity should come out of a source and if it is not then one should "return to the roots".

This work takes into account such an approach of the problem. The cognitive way led from the source with the primary link being the dependence of the path length on time, is expressed in the form of a general differential equation.

At the end it is worth mentioning that the cognitive defects of the classical mechanics are also noticed by other researchers. Author of the work [38] has stated, for instance, that non-linear vibrations are still an open problem, by pointing out inadequacy of the up-to-date knowledge in this matter. Not to develop further this matter, it seems to be the "black box" which covers undiscovered essence of the studied reality.

\section{References}

[1] W. Siuta, Technical mechanics (in Polish), PWSZ, Warszawa 1964.

[2] M. Szymczak (ed.), Dictionary of Polish language (in Polish), PWN, Warszawa 1987.

[3] J. Misiak, General mechanics. Statics and kinematics (in Polish), Vol. 1, WNT, Warszawa 1995.

[4] Collective work: Small guidebook of mechanics (in Polish), WNT, Warszawa 1988.

[5] F. P. Bowden, W. Tabor, Friction and Lubrication of Solids, Oxford 1954.

[6] I. W. Kragielski, M. N. Dobycin, W. S. Kombalow, Grundlagen der Berechnung von Reibung und Verschlei $\beta$. Verlag - Technik, Berlin 1982.

[7] H. Drescher, Zur Mechanik Der Reibung zwischen Festen Körpern, VDJ 1959.

[8] B. W. Dieriagin, What is the friction? (in Polish), PWN, Warszawa 1956.

[9] E. Rabinowicz, Investigation of Size Effects in Slipping by Means of Statistical Techniques, Proc. of the Conf. Lubric. \& Wear, London 1957.

[10] J. Sadowski, Trybologia 6 (1987) 4-6.

[11] J. Sadowski, Trybologia 1 (1988) 10-11.

[12] J. Sadowski, Trybologia 2 (1988) 7-10.

[13] G. Fleischer, Schmierungstechnik, 8 and 9, 1976.

[14] A. Tross, Über das Wesen und den Mechanismus er Festigkeit, Eigenverlag, Münhen und Zell Am See 1966.

[15] F. T. Barwell, Bearing (in Polish), WNT, Warszawa 1984.

[16] F. P. Bowden, W. Tabor, Introduction to tribology (in Polish), WNT, Warszawa 1980. 
[17] M. Gierzyńska, E. Olszewski, M. Przeniosło, Zeszyty Naukowe Politechniki Częstochowskiej. Nauki Techniczne (Mechanika), Częstochowa 23(9) (1973) 77-91.

[18] W. Leszek, W. Zwierzycki, Trybologia 2 (1987) 4-7.

[19] N. P. Suh, H. C. Sin, Wear 69 (1981) 92-114.

[20] Zdzisław Pluta, Some aspects of mutual lapping of alundum ceramics (in Polish), Proc. $4{ }^{\text {th }}$ Confer. On „Abrasive Treatment and Machine Tools”, Łódź, May 1981, pp. 190-193.

[21] Zdzisław Pluta, Energetic aspects of cutting using single abrasive grain fixed flexibly (in Polish), Proc. $23^{\text {rd }}$ Sci. School on Abrasive Treatment. Rzeszów-Myczkowice, September, 2000, pp. 303-309.

[22] Zdzisław Pluta, Potential and the work of single abrasive grain (in Polish), Proc. $25^{\text {th }}$ Sci. School on Abrasive Treatment. Wrocław-Duszniki Zdrój, 11-14 September 2002, pp. 389-394.

[23] Zdzisław Pluta, Determination of energetic potential of compact abrasive tools (in Polish), Proc. $25^{\text {th }}$ Sci. School on Abrasive Treatment. Wrocław-Duszniki Zdrój, 11-14 September 2002, pp. 395-400.

[24] Zdzisław Pluta, Fundamentals of surface smoothing by elastic abrasive wheels (in Polish), Edit. Office of Politechnika Koszalińska, Koszalin 2007.

[25] Zdzisław Pluta, Energetyka 7 (2005) 496-501.

[26] Zdzisław Pluta, Tadeusz Hryniewicz, International Letters of Chemistry, Physics and Astronomy 7(2) (2013) 85-101.

[27] Zdzisław Pluta, LAB (Laboratoria, Aparatura, Badania) 2 (2004) 50-52.

[28] W. Leszek, Zagadnienia Eksploatacji Maszyn 36(2)126 (2001) 33-47.

[29] W. Tarnowski, Computer simulation of continuous processes (in Polish), Wydawnictwo Politechniki Koszalińskiej, Koszalin 1995.

[30] Zdzisław Pluta, Tadeusz Hryniewicz, Intern. J. Adv. Mater. Technol. 62(5) (2012) 529-542, DOI: 10.1007/s00170-011-3813-5.

[31] Zdzisław Pluta, Tadeusz Hryniewicz, International Letters of Chemistry, Physics and Astronomy 3 (2012) 1-10.

[32] Zdzisław Pluta, Tadeusz Hryniewicz, International Letters of Chemistry, Physics and Astronomy 3 (2012) 11-23.

[33] Zdzisław Pluta, Tadeusz Hryniewicz, International Letters of Chemistry, Physics and Astronomy 4 (2012) 1-7.

[34] Zdzisław Pluta, Tadeusz Hryniewicz, International Letters of Chemistry, Physics and Astronomy 4 (2012) 8-16.

[35] Zdzisław Pluta, Tadeusz Hryniewicz, International Letters of Chemistry, Physics and Astronomy 5 (2012) 35-45. 
[36] Zdzisław Pluta, Tadeusz Hryniewicz, International Letters of Chemistry, Physics and Astronomy 4(2013) 56-72.

[37] Z. Osiński, Przeglad Mechaniczny 16 (1996) 11-14.

[38] Z. Dąbrowski, Przegląd Mechaniczny 11 (2007) 15-18. 